\title{
Effect of Boron Micro-alloying on the Surface Tension of Liquid Iron and Steel Alloys
}

\author{
lurii Korobeinikov ${ }^{1}$ (D) Dmitry Chebykin ${ }^{1} \cdot$ Seshadri Seetharaman ${ }^{2}$. \\ Olena Volkova ${ }^{1}$
}

Received: 30 December 2019 / Accepted: 18 February 2020 / Published online: 6 March 2020

(c) The Author(s) 2020, corrected publication 2021

\begin{abstract}
Thermo-physical properties of the liquid metals and alloys play an essential role in modeling and controlling metallurgical processes. In particular, surface tension of metals has a strong impact on wetting various surfaces. Boron is added in numerous iron-based alloys as micro-alloying component. In existing literature, there is no general agreement with the effect of boron on the surface tension. The present study focuses on investigations of boron micro-alloying on the surface tension of iron and CrMnNi alloys by the maximum bubble pressure method (MBP). In contrast to other techniques, maximum bubble pressure technique is less affected by the evaporation of surface-active elements and the purity of the atmosphere around the sample. Measurement of the surface tension was accomplished before and after in situ addition of boron to the molten metal phase. Samples were molten in $\mathrm{ZrO}_{2}$ and $\mathrm{Al}_{2} \mathrm{O}_{3}$ crucibles and yttria-PSZ capillaries were used for the experiments. Measurements were carried out at $1550{ }^{\circ} \mathrm{C}$ in argon atmosphere and argon as bubbles formation media. Results of the experiments indicate a minor effect of boron on the surface tension of liquid iron. Effect of boron on the surface tension of steels is discussed in the context of other surface-active elements present.
\end{abstract}

Keywords Boron $\cdot$ Iron $\cdot$ Maximum bubble pressure $\cdot$ Steel $\cdot$ Surface tension

\footnotetext{
Selected Papers of the 12th Asian Thermophysical Properties Conference.

Iurii Korobeinikov

iurii.korobeinikov@gmail.com

1 Institute of Iron and Steel Technology, TU Bergakademie Freiberg, Freiberg, Germany

2 Royal Institute of Technology (KTH), Stockholm, Sweden
} 


\section{Introduction}

Thermophysical properties of the iron-based alloys play an essential role in the processing of steel and ferroalloys. For example, it is well known that in the process of inert gas atomization, [1,2], physical properties such as surface tension, viscosity, and density of the liquid metal have a serious impact on the process. It is well established that reduction of surface tension leads to the decrease of median particle size of the atomized powder [2, 3]. Within the project CRC 799 TRIP-Matrix-Composites, the effects of sulfur, phosphorus, and selenium on the surface tension of TRIP/TWIP steel alloys have already been studied. Although sulfur and selenium have shown tremendous surface tension reduction effect for medium-manganese TRIP steels [3], these alloying elements may be of little interest for industrial application. Presence of sulfur is not desirable in many alloys. As a possible alternative, boron was previously tested on the liquid iron. Dubberstein et al. [4] have indicated reduction of the contact angle between boron-alloyed iron and alumina substrate compared to the pure iron sample.

A literature survey concerning possible surface-active elements that could be considered as not harmful for further alloy application revealed controversial information on boron. To the knowledge of the authors, one of the earliest investigations on the effect of boron on the surface tension of iron or iron alloys date back to 1954 [5]. In this work, Kreshchanowski et al. studied the effect of additions of $0.06 \%$ to $0.1 \%$ of B into $\mathrm{Cr}-\mathrm{Ni}$ steel with the use of Maximum Bubble Pressure technique (abbreviated henceforth as MBP). It was reported that the additives of boron led to the reduction of surface tension (abbreviated henceforth as ST) from $1400 \mathrm{mN} \cdot \mathrm{m}^{-1}$ to $1200 \mathrm{mN} \cdot \mathrm{m}^{-1}$. In 1961 , Kozakevitch and Urbain measured effect of boron on the ST of iron by the Sessile Drop (abbreviated henceforth as SD) technique [6]. These authors reported that the surface activity of boron on iron melts is not significant. According to the information by Pirogov et al., special experiment made by Blizjukov et al. in 1968 have not revealed any surface activity of Boron [7, 8].

On the other hand, MBP measurements of steel made by Bobkova et al. [9] showed that small additions of boron- 0.04 to $0.1 \%$-led to significant decrease of surface tension. In 1975, El-Wahab et al. [10] have studied the influence of different boron contents $(0-3000 \mathrm{ppm})$ to steel $22 \mathrm{CrMo5}$. It was found by these authors that increasing the boron content leads to constant rise of surface tension.

The most recent study on boron effect on the surface tension of low carbon steel was reported by Mukai et al. [11] who used the sessile drop technique. These authors found no significant effect of boron on the surface tension of the studied steels.

Considering existing works on boron, it may be interesting to note that studies utilizing sessile drop technique were not able to detect surface tension effect on iron and its' alloys. These could be explained by the high sensitivity of the $\mathrm{SD}$ technique to the purity of the atmosphere and sample. On the contrary, those works utilizing MBP technique were able to detect considerable surface tension change due to boron additions. It should be noted that, in MBP technique, atmosphere around the sample does not play a crucial role, as each bubble creates entirely new surface inside a big volume of the metal sample. 
Abovementioned works predefined the choice of MBP as a method for studying the effect of boron on the surface tension of pure liquid iron. The objective of the present investigation is to highlight the effect of boron on the surface tension of extremely pure iron samples and test boron micro-alloying of $\mathrm{Cr}-\mathrm{Ni}-\mathrm{Mn}$ steels.

\section{Experimental}

\subsection{Theoretical Base of Experimental Technique}

In the present work, the measurement of surface tension was accomplished with the use of maximum bubble pressure technique (MBP).

Theoretical principles of the maximum bubble pressure technique are explicitly fully described in the work of Mysels [12]. Maximum pressure in the bubble depends on the surface tension of the liquid $-\sigma$, immersion depth $-\mathrm{h}$, density of the liquid $-\rho$, radius of the capillary $-r$ and is expressed by the Eq. 1:

$$
P_{\text {max }}=\frac{2 \sigma}{r_{\text {capillary }}}+\rho * g * h
$$

Therefore, surface tension of the liquid can be obtained from the Eq. 2

$$
\sigma=0.5 * r_{\text {capillary }}\left(p_{\max }-\rho * g * h\right)
$$

Density of the liquid is obtained as a function of maximum bubble pressure change with the immersion into the liquid, e.g., the angle of the pressure vs. depth line, and can be expressed as Eq. 3:

$$
\rho=\frac{\Delta p_{\max }}{\Delta h * g}
$$

In order to account for the gravity effects, the Schrödinger correction of the surface tension is applied [13]:

$$
\sigma=\frac{r p}{2}\left(1-\frac{2}{3}\left(\frac{r \rho g}{p}\right)-\frac{1}{6}\left(\frac{r \rho g}{p}\right)^{2}\right)
$$

\subsection{Experimental Equipment}

Measurement cell was previously described in [14, 15]. For the current research, it was modified. Actual configuration of the unit is shown in Fig. 1. Maximum bubble pressure is measured with the $\mathrm{ZrO}_{2}\left(\mathrm{Y}_{2} \mathrm{O}_{5}\right.$-stabilized) capillary (2). Sample is placed in the $\mathrm{Al}_{2} \mathrm{O}_{3}$ crucible with $26 \mathrm{~mm}$ inner diameter (8). $\mathrm{Al}_{2} \mathrm{O}_{3}$ crucible is located inside the graphite heating body (3). Graphite body is placed on a ceramic pedestal inside the ceramic furnace (9). Graphite heating body is inductively heated by a copper induction coil inside the walls of the furnace (4). The furnace is movable in 3 
Fig. 1 Scheme of the maximum bubble pressure measurement cell. 1-top gas inlet (argon), 2-capillary, 3-graphite susceptor, 4-induction coil, 5-bottom thermocouple-type B, 6- bottom gas inlet (argon), 7 -electric drive for vertical positioning, 8-crucible, 9induction furnace with ceramic walls, 10 - ceramic cover, $11-$ side thermocouple (type B)

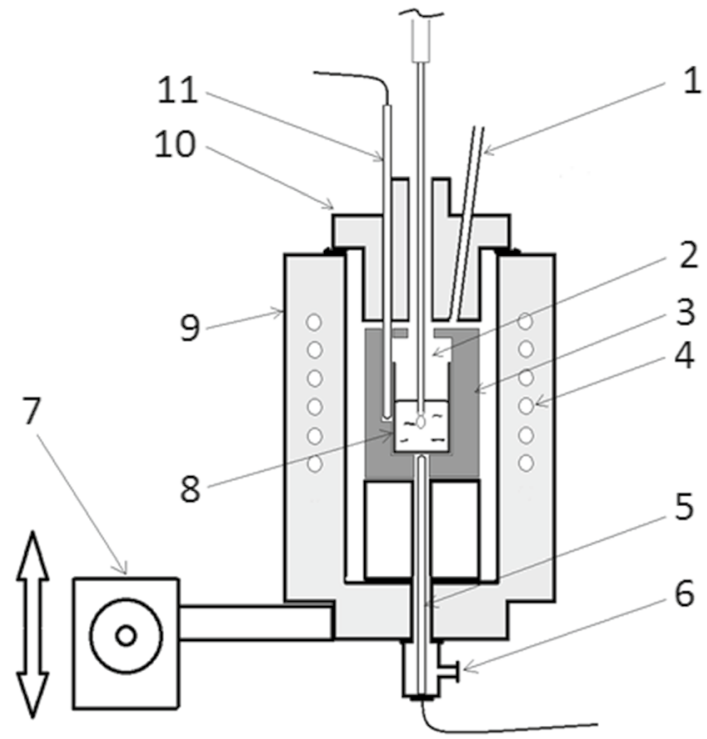

dimensions. Electric drive (7) ensures vertical positioning of the furnace and is controlled to micrometer precision. The furnace is flushed with argon at $250 \mathrm{l} \mathrm{h}^{-1}$ rate from the top (1) and bottom (6). Temperature of the sample is measured by two type $\mathrm{B}$ thermocouples. One thermocouple is placed below the crucible in contact with the bottom (5). Second thermocouple is placed $20 \mathrm{~mm}$ above the bottom in contact with the outer wall of crucible. Typically, the molten sample level is 5-10 mm above the thermocouple level.

Thermocouples' accuracy was calibrated by the immersion of it in a quartz protection into the liquid nickel and measuring the crystallization temperature. Temperature field in crucible was calibrated by two different procedures: (1) immersion of another previously calibrated thermocouple, protected with quartz into the molten copper and comparing the results between side thermocouple and temperature in liquid at various depth and (2) by inserting another thermocouple into the molybdenum cylinder of $25 \mathrm{~mm}$ diameter and $35 \mathrm{~mm}$ height with a central channel of $5 \mathrm{~mm}$ diameter. Second procedure allows to simulate the temperature field in liquid metal without the need to use any kind of thermocouple protection. It is estimated that temperature in the liquid sample is $8-10{ }^{\circ} \mathrm{C}$ less than the temperature measured by the side thermocouple.

\subsection{Materials}

For the present study, two groups of samples were prepared. The first group consisted of iron in the form of ARMCO and electrolytic iron. The second group included two $\mathrm{Cr}-\mathrm{Ni}-\mathrm{Mn}$ steels developed under the CRC799 project. Samples were prepared from iron supplied by the Blyth Metal Limited (electrolytic iron), as well as ARMCO iron. Electrolytic iron was deoxidized with the help of aluminum in 
cold crucible vacuum unit (3 samples of iron were separately deoxidized). Chemical analysis of the metal after deoxidation was as given for Sample 0 in Table 1. Samples of the $\mathrm{Cr}-\mathrm{Ni}-\mathrm{Mn}$ steels were prepared in the laboratory induction furnace VIM-12 (ALD Vacuum Technologies).

Chemical composition of the samples before and after experiments is given in Table 1. Analysis of the chemical composition was accomplished with the use of combustion analyser Bruker G4 Ikarus for carbon and sulfur content measurement, spark spectrometer Oxford Instruments Foundry-master for general analysis of chemical composition.

\subsection{Experimental Procedure}

Procedure of experiments was as follows:

1) The sample was heated in argon atmosphere until $1550^{\circ} \mathrm{C}$. All the measurements were accomplished at the same temperature.

2) Measurement of the surface tension with the MBP technique was performed.

3) Addition of boron to the sample. Alloying was accomplished with the use of lowalloyed steel envelope (pouch) attached to the low-alloyed wire. The envelop was inserted into the furnace through the channel in the ceramic cover and top opening of the graphite susceptor. After inserting the envelop into the liquid sample, it dissolves in the liquid and detaches from the wire. At the time of alloying, the capillary was removed from the furnace.

4) Measurement of surface tension with MBP technique. Procedure was repeated at least two times to assure the reproducibility of the results.

Maximum bubble pressure procedure applied for the iron samples was similar to the one described in $[14,15]$. After finding the melt level by the detection of initial pressure rise inside the capillary, it was immersed to a depth of $10 \mathrm{~mm}$ in the melt. At this depth, the pressure in at least 10 bubbles was measured. The procedure was repeated with further immersions (immersion mode) with $1 \mathrm{~mm}$ interval until the depth of $20 \mathrm{~mm}$ was achieved. The measurement was then continued by decreasing the depth level of the capillary (withdrawal mode) back to $10 \mathrm{~mm}$ immersion depth. Totally 190 bubbles were measured-100 during the increase of immersion depth and 90 during the way back. Then the capillary was completely lifted from the melt. One surface tension data point measurement took between 1 and $1.5 \mathrm{~h}$. Therefore, the sample stayed in the liquid state from 5 to $7 \mathrm{~h}$. Typical profile of the maximum bubbles pressure line is shown in Fig. 2. 


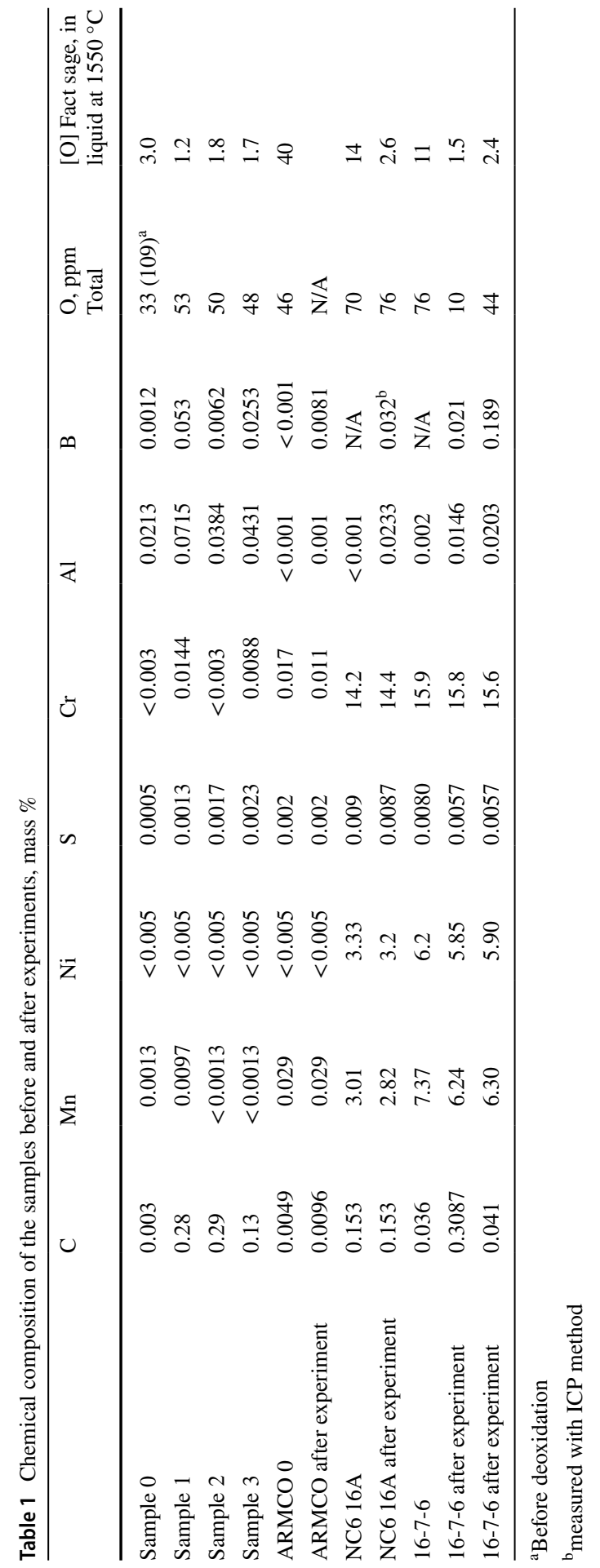


Fig. 2 Typical maximum bubbles pressure on immersion and removal of the capillary

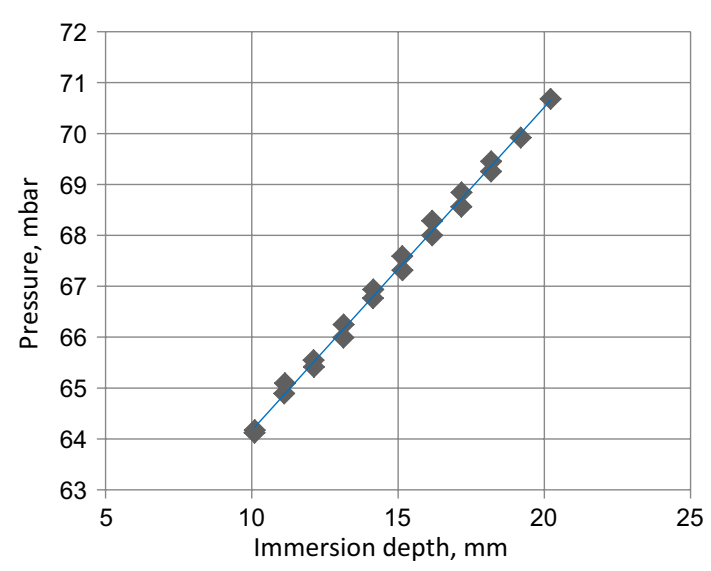

\section{Results and Discussion}

\subsection{Iron Samples}

The first sample investigated was the ARMCO iron. Surface tension of the pure sample was measured twice (after cooling down to room temperature it was molten again) to check the data variations. The scatter in the surface tension values obtained was less than $1 \%$. The results obtained are presented in the form of a staple diagram in Fig. 3. Addition of boron to the sample has changed surface tension towards higher value-2.4\% higher than two clean sample measurements. This indicated that boron increases surface tension of liquid iron. Chemical analysis of the ARMCO sample revealed $46 \mathrm{ppm}$ of total oxygen. Thermodynamic analysis shows that boron can react with oxygen and form $\mathrm{B}_{2} \mathrm{O}_{3}$. This reaction has a strong negative Free Gibbs Energy of $-645911 \mathrm{~J}$ at $1550{ }^{\circ} \mathrm{C}$. From another side, the sample has very low amount of $\mathrm{Al}$. Therefore, boron could bind the free oxygen, which was not already in compound with Al.

In the case of ARMCO iron, the sulfur content is four times more than that electrolytic iron samples before boron addition. Thermodynamic analysis shows that a formation of BS is possible. This could also remove sulfur from the surface of the bubbles, thus increasing the surface tension during experiment.

Fig. 3 Surface tension of ARMCO iron sample before (white) and after (dashed) boron addition at the temperature of $1550{ }^{\circ} \mathrm{C}$

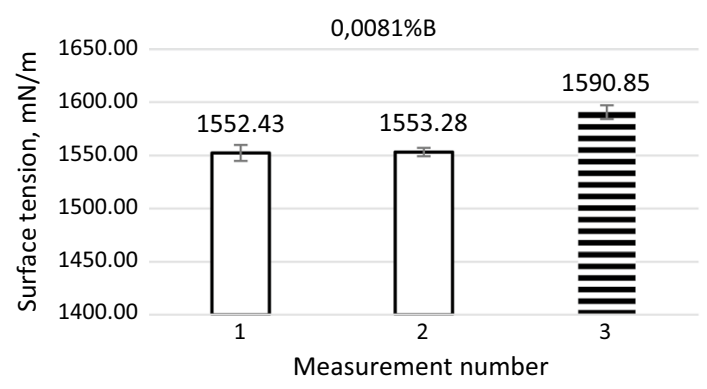


Fig. 4 Surface tension of electrolytic iron before (white) and after (dashed) addition of $0.0062 \%$ boron at $1550{ }^{\circ} \mathrm{C}$
Fig. 5 Surface tension of electrolytic iron before (white) and after (dashed) addition of $0.053 \%$ boron at $1550{ }^{\circ} \mathrm{C}$
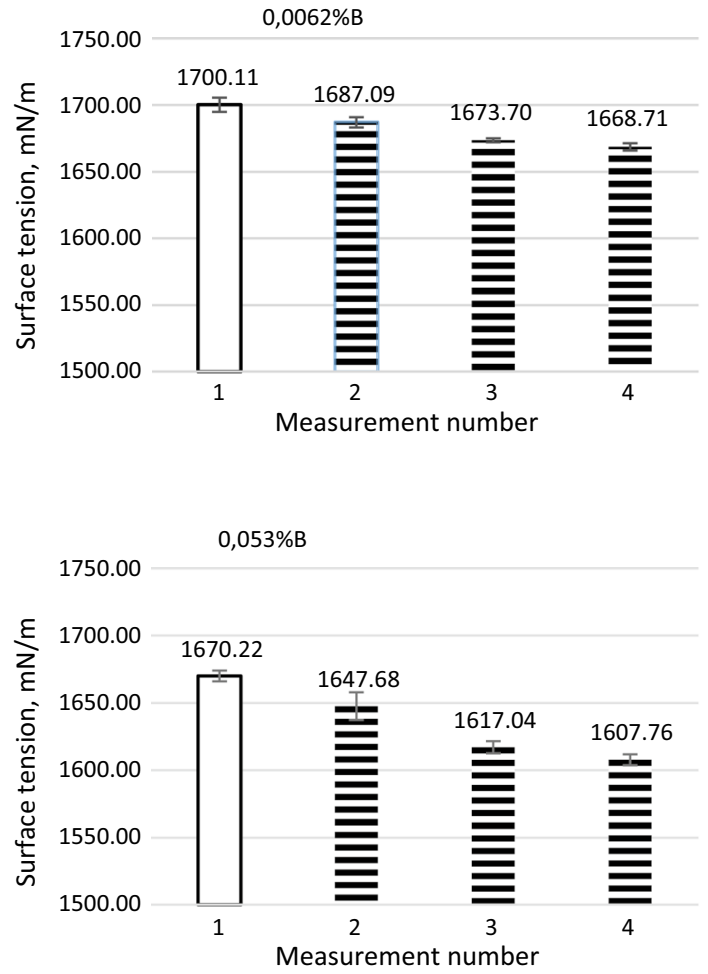

The next series of experiments were conducted with aluminium-deoxidized electrolytic iron. Absolute values of surface tension achieved on pure iron are the maximum values for liquids ever measured on our MBP cell. It is necessary to mention the quite significant variation of surface tension for clean samples-1700 $( \pm 5.4), 1670( \pm 4.3)$, and $1640( \pm 1.3) \mathrm{mN} \cdot \mathrm{m}^{-1}$. Such variation can be explained by deoxidation of each sample separately. However, obtained ST of pure iron is considerably lower than maximum values reported in the literature, which are usually in the range of 1800 to $2000 \mathrm{mN} \cdot \mathrm{m}^{-1}[11,16,17]$. Such discrepancy of our results can stem from the purity of the samples, as well as from purity of the argon gas containing 3-5 ppm oxygen, used to blow the bubbles in the sample.

Experimental results revealed very minor effect of boron on the surface tension. As can be seen in Fig. 4, at the smallest additions of boron $(0.0062 \%)$, surface tension dropped first by $0.77 \% .3$ subsequent repetitions have shown decrease of surface tension with time viz. $1.55 \%$ on a second measurement and $1.85 \%$ on the third one. However, when more boron is added, surface tension change with time is more significant: $0.053 \% \mathrm{~B}$ led to $1.35,3.18$, and $3.74 \%$ consequent reduction (Fig. 5).

In order to confirm this reduction in the surface tension by boron addition, one more trial was carried out with intermediate boron content $(0.0253 \%)$. In this experiment, shown in Fig. 6, only two measurements after boron addition were made. Surprisingly, surface tension dropped in the first measurement only by $0.89 \%$ and 
Fig. 6 Surface tension of the electrolytic iron before (white) and after (dashed) addition of $0.0253 \%$ boron at $1550{ }^{\circ} \mathrm{C}$

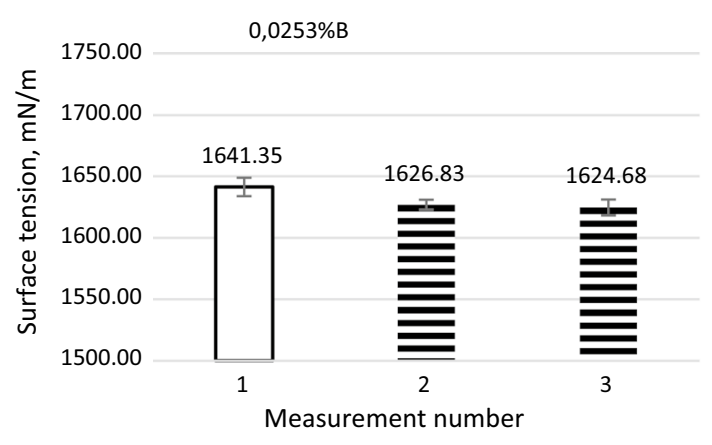

then further changed only marginally $(1.03 \%$ less than the surface tension of the sample before alloying.

Surface tension behavior of all 3 electrolytic iron samples indicated that boron had almost no effect on the surface tension. For the first sample of electrolytic iron with the smallest boron addition, a gradual reduction of surface tension with time may be associated with the better distribution of boron in the volume of the sample. Besides, sample had minor change of sulfur content from 5 ppm to 13 ppm. However, when more boron was added, the decline in the surface tension was higher. At the same time, the second sample had almost the same changes in post-treatment chemical analysis (negligible difference in $\mathrm{C}, \mathrm{O}$, and $\mathrm{S}$ contents) as the sample with $0.0062 \%$. It indicates that reduction of the surface tension of iron is associated only with the effect of boron.

Observed slight decrease of surface tension after boron addition and further ST decline in next measurements could be attributed not only to the effect of boron, but also to carburisation of the sample. Initial samples were having around $30 \mathrm{ppm}$ of carbon. Post-experiment chemical analysis showed significant increase of carbon content-up to $0.29 \%$. Although carbon is not known as a surface-active element, some researchers reported either positive or negative ST effect of it. According to Lee and Morita [17], when the sulfur content of the iron is very low-10 PPM or less - carbon positively affects surface tension. Jimbo et al. [18] suggested that if sulfur content is over 70 PPM,carbon may increase the activity of sulfur, which negatively affects surface tension. In our study, amount of sulfur in the samples after experiments fall within the range of 10 PPM $<$ S $>25$ PPM. It means that the carbon content should not significantly affect surface tension. Therefore, most likely, surface change decrease should be attributed to the effect of boron alloying. The effect of boron alloying on the surface tension of pure iron can be summarized in the Fig. 7, as shown below.

\subsection{Cr-Ni-Mn Steel Samples}

The first steel sample investigated with the MBP technique was $15 \% \mathrm{Cr} 3 \% \mathrm{Ni} 3 \% \mathrm{Mn}$ alloy. Surface tension of this alloy was not reported earlier. It was estimated as $1266( \pm 2) \mathrm{mN} \cdot \mathrm{m}^{-1}$ in the first run (before B-alloying). After addition of $0.032 \% \mathrm{~B}$, surface tension increased to $1306( \pm 5) \mathrm{mN} \cdot \mathrm{m}^{-1}$ in the 


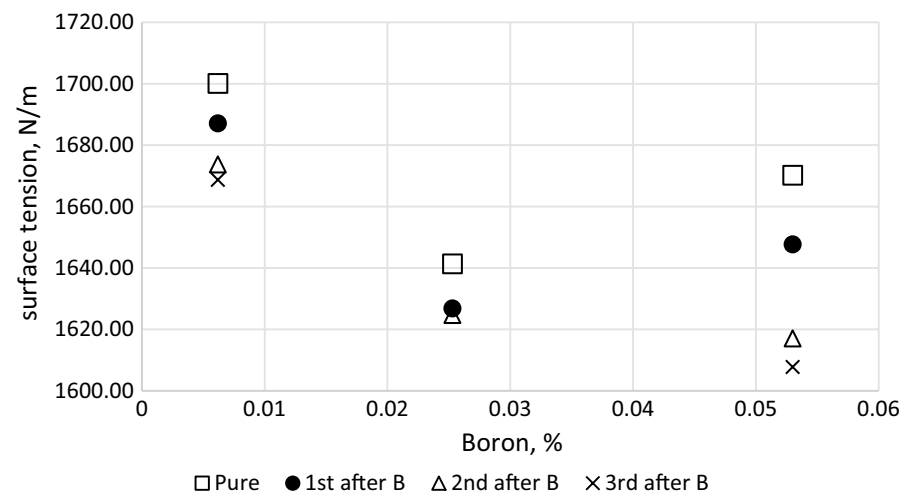

Fig. 7 Surface tension of the liquid iron as a function of boron content at $1550{ }^{\circ} \mathrm{C}$

second and to $1299( \pm 1) \mathrm{mN} \cdot \mathrm{m}^{-1}$ in the third run (Fig. 8). It corresponds to 3.16 and $2.61 \%$ increase from the initial level. No carburisation of the sample and no change in oxygen and sulfur was detected during this experiment.

Further investigation of boron micro-alloying for $16 \% \mathrm{Cr} 6 \% \mathrm{Ni} 7 \% \mathrm{Mn}$ alloy showed very similar results. Initial surface tension of this steel was measured as $1261( \pm 1.6) \mathrm{mN} \cdot \mathrm{m}^{-1}$ (Fig. 9). This value is considerably higher than that previously reported for this alloy $[14,19]$. Such a difference can possibly be explained by higher carburisation of the compared to [14, 19] the much lower level of total oxygen-10 PPM - in the sample after experiment. Nevertheless, addition of boron resulted in an increase of surface tension to $1290( \pm 1.75) \mathrm{mN} \cdot \mathrm{m}^{-1}$ in

Fig. 8 Surface tension of the liquid $15 \% \mathrm{Cr}-3 \% \mathrm{Ni}-3 \% \mathrm{Mn}$ steel before (white) and after (dashed) addition of $0.032 \% \mathrm{~B}$ at $1550{ }^{\circ} \mathrm{C}$
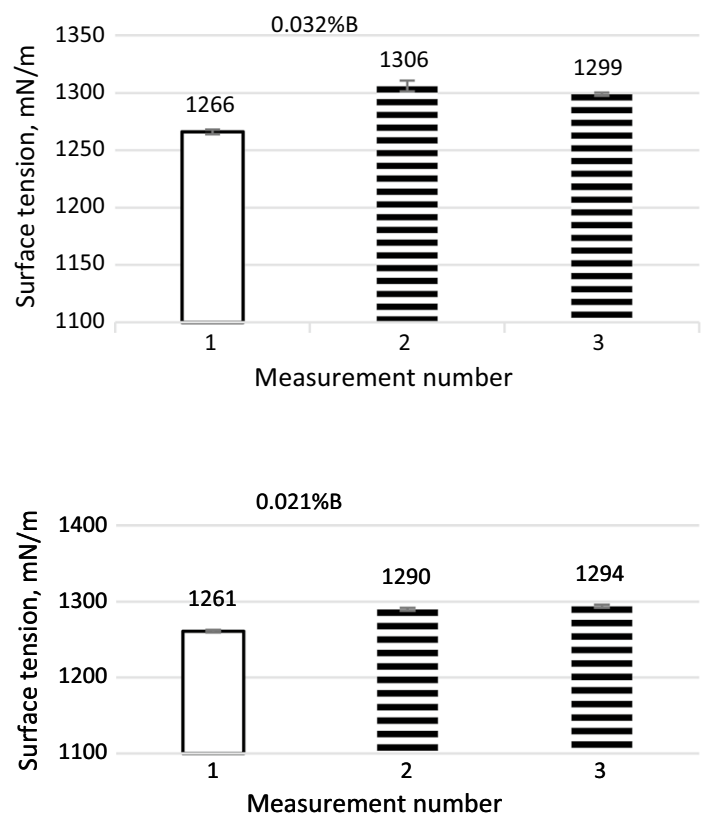

Fig. 9 Surface tension of the $16 \% \mathrm{Cr}-6 \% \mathrm{Ni}-7 \% \mathrm{Mn}$ steel before (white) and after (dashed) addition of $0.021 \% \mathrm{~B}$ at $1550{ }^{\circ} \mathrm{C}$ 
the second and to $1294( \pm 2) \mathrm{mN} \cdot \mathrm{m}^{-1}$ in the third run. Relative ST changes were +2.3 and $+2.6 \%$, respectively.

The third steel sample was decided to be alloyed with a significantly greater amount of boron. Therefore, as much as $0.189 \%$ of B was added to the sample. As it can be seen from the Fig. 10, initial surface tension of the alloy in this experiment was slightly lower than that in the first one-1220 $( \pm 2.8) \mathrm{mN} \cdot \mathrm{m}^{-1}$. Posttreatment chemical analysis detected growth of $\mathrm{C}$ content on $\sim 50 \mathrm{ppm}$; thus, no significant carburisation of the sample occurred. Additionally, oxygen content declined from $76 \mathrm{ppm}$ to $46 \mathrm{ppm}$. After boron addition, surface tension of the liquid $16 \% \mathrm{Cr}-6 \% \mathrm{Ni}-7 \% \mathrm{Mn}$ steel has significantly decreased. In the second run, ST was measured as $1154( \pm 3.3) \mathrm{mN} \cdot \mathrm{m}^{-1}$ and in the third run, ST was measured as $1132( \pm 2.6) \mathrm{mN} \cdot \mathrm{m}^{-1}$. Relative reduction of surface tension was $5.4 \%$ and $7.4 \%$, respectively. These results present an unusual trend. Surface tension of initial alloy is relatively low due to high-content surface-active elements like $\mathrm{S}$ and O. Also, this steel has $7 \%$ of Mn, which is known for its ST reduction effect [20]. Significant ST reduction in our experiment contradicts to the results of El-Wahab et al. [10]. These authors obtained a well detectable ST increase in the range of $0.05 \%$ to $0.3 \%$ boron in the steel. The steel samples used in their experiments contained approximately 200 ppm of sulfur and 100-264 ppm of oxygen. El-Wahab suggested that boron must bound some amounts of dissolved oxygen and remove it from the liquid surface. Our experiments show that, in the presence of significant oxygen amounts, boron increases surface tension of iron and steel. These were the cases of ARMCO sample, $15 \% \mathrm{Cr}-3 \% \mathrm{Mn}-3 \% \mathrm{Ni}$, and first $16 \mathrm{Cr} \%-7 \% \mathrm{Mn}-6 \% \mathrm{Ni}$ sample. However, when there is almost no free oxygen left in the melt, boron moderately lowers surface tension of the iron. These were the cases of electrolytic iron and sample of $16 \% \mathrm{Cr}-7 \% \mathrm{Mn}-6 \% \mathrm{Ni}$ steel with $0.189 \%$ of boron added.

Ambiguous effect of boron on the surface tension of steel was previously reported by Bobkova et al. [9], who found a decrease of surface tension at $0.04 \%$ and $0.1 \%$ $\mathrm{B}$, while a slight ST increase was detected at $0.17 \% \mathrm{~B}$ added to the vanadium-alloyed $(0.27 \%)$ steel. Unfortunately, that work did not present detailed data on the experimental conditions and amounts of oxygen, sulfur, and other important elements in the samples which are critical for surface tension of liquid steel. The same problem arises when the present results are compared with those of Kreshchanovski et al. [5] - no information on the oxygen and sulfur content of the samples is available.

Fig. 10 Surface tension of the $16 \% \mathrm{Cr}-6 \% \mathrm{Ni}-7 \% \mathrm{Mn}$ steel before (white) and after (dashed) the addition of $0.189 \% \mathrm{~B}$ at $1550{ }^{\circ} \mathrm{C}$

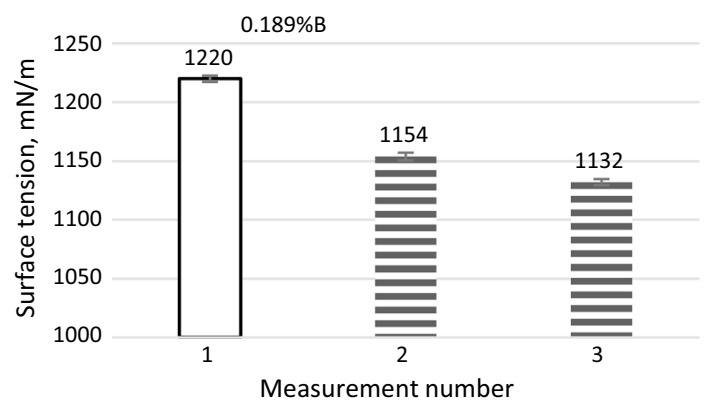




\subsection{Density}

Maximum bubble pressure allows to simultaneously gain information on the surface tension and density of the measured liquid. As can be seen from the Eq. 2, density obtained from the measurement allows to calculate the surface tension of the liquid in the present study. As can be seen in the Fig. 11, a sum of 3 density points at $1550{ }^{\circ} \mathrm{C}$ was obtained for $15 \mathrm{Cr} 3 \mathrm{Mn} 3 \mathrm{Ni}$ alloy and 6 for $16 \mathrm{Cr} 7 \mathrm{Mn} 6 \mathrm{Ni}$ alloy. Density of the ARMCO and electrolytic iron should be treated as one dataset due to negligible chemical composition differences. As a result of 14 datapoints obtained, density of the liquid iron in present work is defined as $6831.81( \pm 209.7) \mathrm{kg} \cdot \mathrm{m}^{-3}$. This value is $2.8 \%$ less than the recommended value for iron at the temperature of $1550{ }^{\circ} \mathrm{C}$ [21]. Steel alloys density was estimated as $6825.67( \pm 68.24) \mathrm{kg} \cdot \mathrm{m}^{-3}$ and 6777.17 $( \pm 262.75) \mathrm{kg} \cdot \mathrm{m}^{-3}$ for $15 \mathrm{Cr} 3 \mathrm{Mn} 3 \mathrm{Ni}$ and $16 \mathrm{Cr} 7 \mathrm{Mn} 6 \mathrm{Ni}$, respectively. $16 \mathrm{Cr} 7 \mathrm{Mn} 6 \mathrm{Ni}$ alloy density is almost identical to $6787 \mathrm{~kg} \cdot \mathrm{m}^{-3}$ reported for $16 \mathrm{Cr} 7 \mathrm{Mn} 3-9 \mathrm{Ni}$ steels by Dubberstein et al. [22]. As for $15 \mathrm{Cr} 3 \mathrm{Mn} 3 \mathrm{Ni}$ alloy, it's higher density should stem from the smaller manganese content in the liquid. Generally, it can be stated that density values for both liquid iron and $\mathrm{CrMnNi}$ steels obtained in the present research work are in good agreement with the existing literature.

\section{Conclusions}

Experimental investigation of boron effect on the surface tension of liquid iron at $1550{ }^{\circ} \mathrm{C}$ with the use of maximum bubble pressure technique was carried out in the present work. Tests show that the effect of boron on the surface tension of electrolytic iron is quite low. Surface tension dropped by a significant extent, viz. $3.74 \%$ at $0.053 \%$ of boron addition. Surface tension was slowly decreasing with time. Density values obtained in this study are in good agreement with the existing literature.

In contrary, samples of TRIP/TWIP steel and ARMCO iron showed moderate increase of the surface tension after additions of $0.03 \%$ to $0.02 \%$ of boron. At the

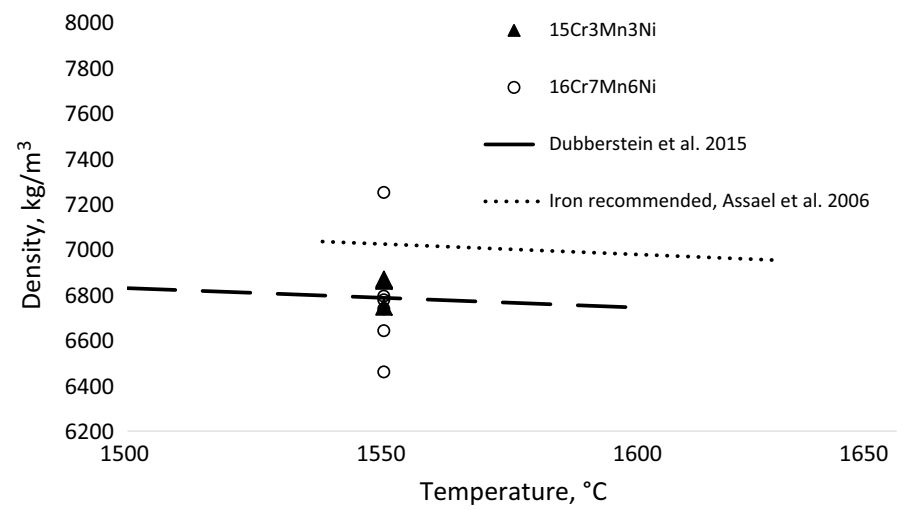

Fig. 11 Density of CrMnNi steels measured in this study at $1550{ }^{\circ} \mathrm{C}$ in comparison with the literature sources 
same time, addition of $0.189 \%$ B led to strong surface tension reduction of steel. Such ambiguous behaviour of surface tension of steel cannot be attributed to variations in the contents of other surface-active elements. Most likely, when liquid iron contains free oxygen, boron binds some amount of it. At the diminishing amounts of free oxygen, boron acts as a surface-active element lowering surface tension.

More detailed research on this topic with various iron and steel samples that could reveal the mechanisms of boron effects on the surface tension of iron are currently planned as future work.

\section{Appendix}

\section{Experimental Uncertainty}

Uncertainty of the measurement was calculated by the following equations:

$$
\begin{gathered}
S_{\sigma}^{2}=\left(\frac{\partial \sigma}{\partial r}\right)^{2} * S_{r}^{2}+\left(\frac{\partial \sigma}{\partial p}\right)^{2} * S_{p}^{2}+\left(\frac{\partial \sigma}{\partial \rho}\right)^{2} * S_{\rho}^{2}+\left(\frac{\partial \sigma}{\partial T}\right)^{2} * S_{T}^{2}+\left(\frac{\partial \sigma}{\partial h}\right)^{2} * S_{h}^{2}=1 \% \\
S_{\rho}^{2}=\left(\frac{\partial \rho}{\partial p}\right)^{2} * S_{p}^{2}+\left(\frac{\partial \rho}{\partial h}\right)^{2} * S_{h}^{2}+\left(\frac{\partial \rho}{\partial T}\right)^{2} * S_{T}^{2}=2 \%
\end{gathered}
$$

The main effect on the uncertainty of the measurement of surface tension and density is coming from the radius of the capillary and surface level of the liquid.

Temperature variations with time during the measurement are in the range of $\pm 1{ }^{\circ} \mathrm{C}$. Uncertainty of the Typ B thermocouple is $0.25 \%$ which gives a maximum temperature deviation of $\pm 4{ }^{\circ} \mathrm{C}$ at $1600{ }^{\circ} \mathrm{C}$. Calibration with the liquid copper showed that temperature in the liquid is deviating at $\pm 1{ }^{\circ} \mathrm{C}$. All together gives a $\pm 5{ }^{\circ} \mathrm{C}$ temperature uncertainty.

Immersion of the capillary is measured with the precision of $0.005 \mathrm{~mm}$. Contact point (surface level) of the capillary with the liquid is defined with the precision of $0.01 \mathrm{~mm}$ which gives a total position uncertainty of $0.01 \mathrm{~mm}$. However, surface level of the liquid can change with $\pm 1 \mathrm{~mm}$ during the measurement of one temperature point.

Capillary radius is measured with the uncertainty of $0.005 \mathrm{~mm}$. This gives a ST deviation of $0.86 \%$. Radius changes after the experiment were not observed.

Zero-level pressure of the liquid can vary during the experiment between $0 \mathrm{~Pa}$ and $20 \mathrm{~Pa}$, which gives a ST error of max $0.9 \%$

Acknowledgements This work was Funded by the Deutsche Forschungsgemeinschaft (DFG, German Research Foundation)_Projektnummer: 54473466-SFB 799.

Funding Open access funding enabled and organized by Projekt DEAL.

Open Access This article is licensed under a Creative Commons Attribution 4.0 International License, which permits use, sharing, adaptation, distribution and reproduction in any medium or format, as long as you give appropriate credit to the original author(s) and the source, provide a link to the Creative Commons licence, and indicate if changes were made. The images or other third party material in this article 
are included in the article's Creative Commons licence, unless indicated otherwise in a credit line to the material. If material is not included in the article's Creative Commons licence and your intended use is not permitted by statutory regulation or exceeds the permitted use, you will need to obtain permission directly from the copyright holder. To view a copy of this licence, visit http://creativecommons.org/licen ses/by/4.0/.

\section{References}

1. A.J. Yule, J.J. Dunkley, Atomization of melts for powder production and spray deposition (Clarendon Press; Oxford University Press, Oxford, 1994)

2. T. Dubberstein, H.-P. Heller, Steel Res. Int. 84, 845 (2013)

3. T. Dubberstein, Beiträge zu den thermophysikalischen Eigenschaften flüssiger Metallschmelzen, (PhD Thesis, TU Bergakademie Freiberg, 2015)

4. T. Dubberstein, A. Jahn, M. Lange, H.-P. Heller, P.R. Scheller, Steel Res. Int. 85, 1220 (2014)

5. N.S. Kreshchanowski, W.I. Prosvirin, E.S. Ginsberg, Metal. Giessereitech 4, 529 (1954)

6. P. Kozakevitch, G. Urbain, Mem. Sci. Rev. Met. LVIII, 931 (1961)

7. N.A. Pirogov, J.V. Krjakovski, E.I. Tjurin, Izv. Vys. Uč. Zav., Cher. Met. 3, 45 (1970)

8. S. A. Blizjukov, N. A. Pirogov, Ju. V. Krjakovski, in (KGU, Chisinau, 1968), p. 57

9. O.S. Bobkova, I.A. Evtjuhina, L.P. Kunin, V.S. Petukhov, Surface effects in melts and solid phases formed from them (KBGU, Nalchik, 1965) (Nalchik, KBGU, 1965), pp. 338-340

10. O.M.A. El-Wahab, E. Giza, H. Burghardt, H.J. Eckstein, Neue Hütte 7, 390 (1975)

11. K. Mukai, L. Zhong, M. Zeze, ISIJ Int. 46, 1810 (2006)

12. K.J. Mysels, Colloid Surface. 43, 241 (1990)

13. E. Schrödinger, Ann. Phys. Berlin 351, 413 (1915)

14. T. Dubberstein, H.-P. Heller, Adv. Eng. Mater. 15, 583 (2013)

15. T. Dubberstein, M. Hötzel, R. Hagemann, P. Heller, P.R. Scheller, Steel Res. Int. 82, 1122 (2011)

16. J. Brillo, Thermophysical properties of multicomponent liquid alloys, 1 st edn. (De Gruyter, Berlin, 2016), p. 152

17. J. Lee, K. Morita, Steel Res. 73, 367 (2002)

18. I. Jimbo, A. Sharan, A.W. Cramb, I \& SM 21, 48 (1994)

19. T. Dubberstein, P.R. Scheller, Scientific reports on resource issues (Freiberg, TU Bergakademie Freiberg, 2011), p. 7

20. J. Lee, L. Thu Hoai, M. Shin, Metall. Mater. Trans. B 42, 546 (2011)

21. M.J. Assael, K.D. Kakosimos, M. Bannish, J. Brillo, I. Egry, R. Brooksm, P.N. Quested, K.C. Mills, A. Nagashima, Y. Sato, W.A. Wakeham, J. Phys. Chem. Ref. Data 35, 285 (2006)

22. T. Dubberstein, H.-P. Heller, J. Klostermann, R. Schwarze, J. Brillo, J. Mater. Sci. 50, 7227 (2015)

Publisher's Note Springer Nature remains neutral with regard to jurisdictional claims in published maps and institutional affiliations. 